\title{
FTIR Analysis of Siddha Medicine Chandra Prabhava Chendooram
}

\author{
Packia Sri $D^{1}$, Kingsly $A^{2}$ \\ ${ }^{1}$ PG Scholar, ${ }^{2}$ Reader and Head of the Department, \\ Department of Gunapadam, Government Medical College, Palayamkottai, Tamil Nadu \\ Corresponding Author: Packia Sri D
}

\begin{abstract}
Background: The Siddha system of medicine is one among part of the AYUSH system. The Siddha medicine is used to treat various diseases, especially in Genital tract diseases. In siddha system medicines were prepared from Herbals, Minerals, salts, and Metals as well as the marine and animal products are also used in the system. The drug CHANDRA PRABHAVA CHENDOORAM is basically a crystal powder in nature which is used in Siddha medicine for Genital tract disorders.

Objective: To explore the elemental characterization of the mineral Chandra prabhava chendooram.

Methods: The Functional Group studied through FTIR study. It can be correlated in WHO recommended parameters for confirmed the standardizations in above drug.

Results: In FTIR studies should markedly increase value from 3678.25 to 3745.76 respectively, which is indicated it contains most of them.

Conclusion: All the modern scientific parameters provide it is minimal size particles and good characteristic nature of the drug. So, Chandra prabhava chendooram is highly therapeutic and bio availability value used cured in genital tract disease.
\end{abstract}

Keywords: Chandra prabhava chendooram, FTIR, Siddha Medicine, genital tract disease

\section{INTRODUCTION}

The World Health Organization (WHO) is estimated that $80 \%$ of populations were used traditional medicine developing countries for primary health care needs (WHO Guidelines-2007). In that way, Siddha medicine has profound vital role in disease, prevention and prophylaxis through its herbal medicine and other form of medicine like chendooram, Parpam and other32 types of preparation (Thiyagarajan.R-2006). The standardization of drug and clinical efficacy of study in chandra prabava chendooram (anuboga vaithiya navaneetham $4^{\text {th }}$ edithion-page-61), here performed the Spectroscopic standardization of chandra prabava chendooram.

The spectroscopic standardization Scanning electron micros coping, Energy
Dispersion X-ray Spectrometric analysis and Infrared (FTIR) studies were used, and results was documented. The spectroscopic standardization to help the reducing the adulteration and definitely helps to understand the characterization of selected ingredients. Modern parameters are very useful to find out the drug adulteration and misidentification. The unidentified chemical compounds, physiochemical compounds were produced hazards to human health. So, Indian system of medicine is needed to standardization. So, saint siddhars were used purification methods (suththi muraigal). In ancient periods, the structural standardization will be proved via spectroscopic studies and FTIR analysis. As per guidelines of WHO and AYUSH insisted the guidelines for quality control to better standardization of the drugs as pertain 
to Pharmacopeia Laboratory of Indian Medicine (PLIM).The Systematic steps should be taken to standardization of traditional drugs by using modern technique like FTIR. In siddha text "ANUPOGA VAITHIYA NAVANEETHAM $4^{\mathrm{TH}}$ EDITION" page no.61 is mentioned the indication of women's genital disorder

\section{MATERIALS AND METHODS}

Required ingredients:

- Purified ilingam-17.5 gram

- $\quad$ purified indhuppu-17.5 gram

\section{PURIFICATION OF INGREDIANTS:}

ILINKAM: Ilinkam was taken as a single mass. Equal part of lemon juice, cow's milk, and acalypha juice were mixed together and were kept in a beaker. Nearly $160 \mathrm{ml}$ juice for 17.5 gram ilinkam.

Ilinkam was kept in a clay plate and heated.

The mixture of juice was added by drop by drop on the surface of ilinkam and it was side to side to wet all part by the juice. When juice were evaporated completely again drop of mixture poured into the plate, it was continued till all the juice was used up. This is described as churukku in siddha medicine

INDHUPPU (ROCK SALT): Soaked in vinegar for 3 days and kept in sunlight for drying.

\section{PROCESS}

The above purified drugs are powdered and triturated for one hour in stone moter. Then it is stored in an airtight bottle. When it is kept in paper it will be moisturized. So it will be kept in air tight container.

\section{DOSAGE: 65-130MG}

ADJUVANT: Palm jaggery, paste of young neem leaf, dried ginger paste.

\section{RESULT}

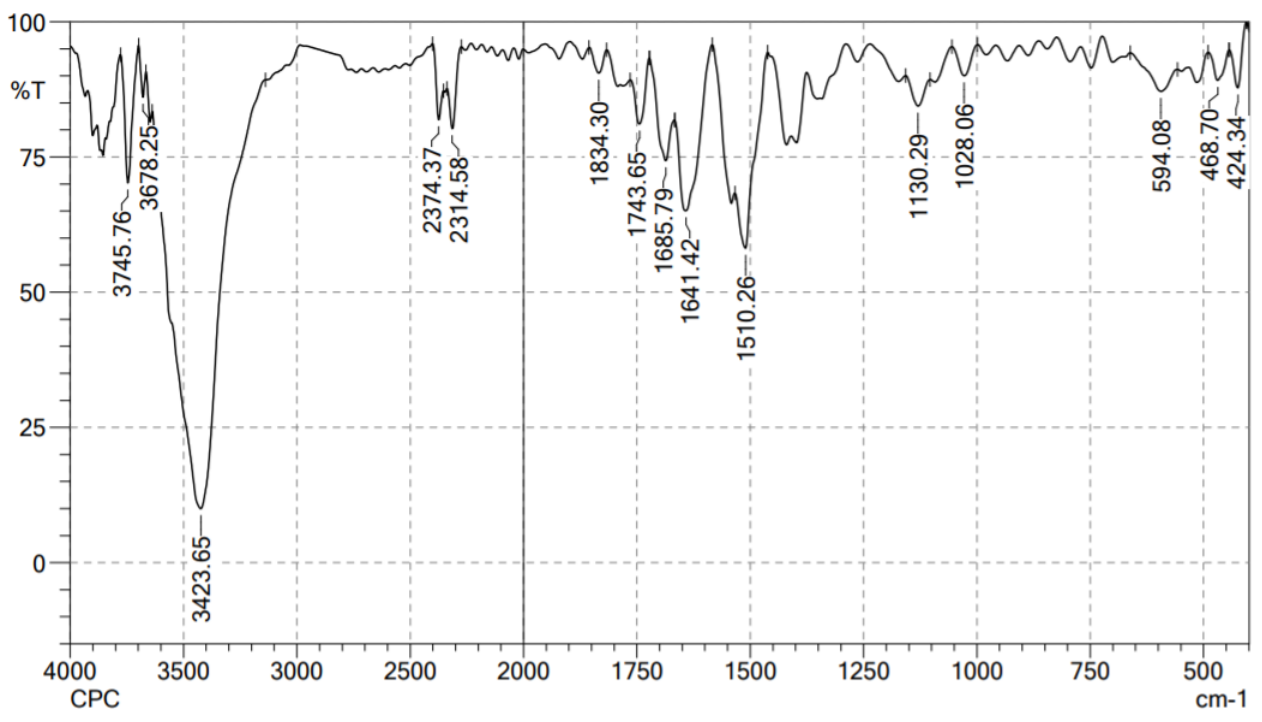

\begin{tabular}{|l|l|l|l|}
\hline Wave Length & Appearance & Group & Compound \\
\hline 1028.06 & Strong & $\mathrm{S}=\mathrm{O}$ stretching & Sulfoxide \\
\hline 1510.26 & Strong & $\mathrm{S}=\mathrm{O}$ stretching & Nitro Compound \\
\hline 1641.42 & Medium & $\mathrm{C}=\mathrm{C}$ stretching & Alkene \\
\hline 1648.79 & Strong & $\mathrm{S}=\mathrm{O}$ stretching & Conjugated Aldehyde \\
\hline 1648.79 & Strong & $\mathrm{C}=\mathrm{O}$ stretching & Acid halide \\
\hline 1834.3 & Strong & $\mathrm{C}=\mathrm{O}$ stretching & Conjugated Acid Halide \\
\hline 3678.25 & Medium Sharp & O-H Group & Alcohol \\
\hline 3745.76 & Medium Sharp & O-H Group & Alcohol \\
\hline
\end{tabular}


INTERPRETATION in FTIR spectra analysis, the values are recorded 1028.06, $1510.26, \quad 1641.42, \quad 1648.79, \quad 1648.79$, 1834.3, 3678.25, 3745.76. Waive Numbers and Group $\mathrm{S}=\mathrm{O}$ stretching, $\mathrm{C}=\mathrm{C}$ stretching, $\mathrm{C}=\mathrm{O}$ stretching etc., and compounds Sulfoxide, Nitro Compound

They protect against bacterial and fungal infections.

\section{CONCLUSION}

In Siddha System of medicine is bio effective and safe therapeutic potentials of Chandra prabhava chendooram on the track and the above data showed that the spectroscopic standardization of the drug. Conclusion is FTIR studies showed no harmful chemicals and minerals etc. So, Chandra prabhava chendooram is safe to use in long period. The further research work must be carried out for the development of scientific data to hold the drug in a scientific manner.
Conflict of Interest: None

\section{Source of Funding: None}

Ethical Approval: Approved

\section{REFERENCES}

1. WHO guidelines for assessing quality of herbal medicines with reference to contaminants and residues, World Health Organization, Geneva, 2007.

2. Thiyagarajan. R, Siddha Materia Medica Mineral\& Animal section, Dept of Indian Medicine and Homeopathy, Chennai, Govt of Tamilnadu, 2006, 686-88

3. Thiyakarajan. R, Gunapadam Thathu Jeeva vaguppu, 2st Edition, Published by Department of Indian Medicine and Homeopathy, 2016.

How to cite this article: Packia Sri D, Kingsly A. FTIR analysis of siddha medicine chandra prabhava chendooram. Int J Health Sci Res. 2021; 11(5): 133-135. DOI: https://doi.org/ 10.52403/ijhsr.20210519

Acknowledgement: None 